\title{
Static and Dynamic Stability Analysis of an Asymmetric Rotating Tapered Sandwich Beam Subjected to Pulsating Axial Load with Thermal Gradient
}

\author{
Madhusmita Pradhan and Pushparaj Dash \\ Department of Mechanical Engineering, Veer Surendra Sai University of Technology, Burla, India, 768018.
}

(Received 23 March 2017; accepted 2 March 2018)

The static and dynamic stability of an asymmetric rotating tapered sandwich beam subjected to pulsating axial load in temperature environment is studied under two different boundary conditions. The non-dimensional equations of motion and the boundary conditions are derived by applying Hamilton's energy principle. A coupled Hill's equations with complex coefficients are derived from the non-dimensional equations of motion by the application of the generalized Galerkin method. By the application of the Saito-Otomi conditions, zones of instabilities are obtained and presented graphically. For the calculation of the Young's module for the elastic layers, the effect of temperature has been taken in to consideration by means of a uniform thermal gradient along the longitudinal axes for both the upper and lower elastic layers. The effects of the taper parameter, core loss factor, thermal gradient, rotational speed, hub radius, and core density parameter on the static buckling loads and the regions of instability are investigated.

\section{LIST OF SYMBOLS}

\begin{tabular}{|c|c|c|c|}
\hline$A_{i}(i=1,2,3)$ & $\begin{array}{l}\text { Areas of cross section of a } 3 \text { layered } \\
\text { beam, } i=1 \text { for top layer }\end{array}$ & $U_{i}(x, t)(i=1,3)$ & $\begin{array}{l}\text { Axial displacement at the middle of } \\
i^{\text {th }} \text { layer of beam }\end{array}$ \\
\hline$B$ & Width of beam & $w(x, t)$ & Transverse deflection of beam \\
\hline$E_{i}(i=1,2,3)$ & Young's module, $i=1$ for top layer & $w^{\prime}$ & $\frac{\partial w}{\partial x}$ \\
\hline$G_{2}^{*}$ & $\begin{array}{l}G_{2}(1+j \eta), \text { complex shear modulus } \\
\text { of core }\end{array}$ & $\begin{array}{l}w^{\prime \prime} \\
\bar{w}\end{array}$ & $\begin{array}{l}\frac{\partial^{2} w}{\partial x^{2}} \\
\frac{w}{l}\end{array}$ \\
\hline$g^{*}$ & $g(1+j \eta)$, complex shear parameter & $\ddot{\bar{w}}$ & $\frac{\partial^{2} \bar{w}}{\sigma^{-2}}$ \\
\hline$g$ & Shear parameter & $\overline{w^{\prime \prime}}$ & $\begin{array}{l}\partial \bar{t}^{2} \\
\partial^{2} \bar{w}\end{array}$ \\
\hline$b$ & $\begin{array}{l}\text { Distance of the nearer end of the beam } \\
\text { from the axis of rotation (hub radius) }\end{array}$ & $U_{i, x}(i=1,3)$ & $\begin{array}{l}\frac{\partial \bar{x}^{2}}{\partial x} \\
\frac{\partial U_{i}}{x}\end{array}$ \\
\hline $\bar{b}$ & $b / l$ & $\bar{x}$ & $\frac{x}{l}$ \\
\hline & Shear strain in the core & $\rho_{i}$ & Density of $i^{\text {th }}$ layer \\
\hline $2 h_{i}(i=1,2,3)$ & $\begin{array}{l}\text { Thickness of the } i^{\text {th }} \text { layer, } i=1 \text { for } \\
\text { top layer }\end{array}$ & $\begin{array}{l}u_{1}^{\prime} \\
\bar{u}_{1}^{\prime \prime}\end{array}$ & $\begin{array}{l}\frac{\partial u_{1}}{\partial x} \\
\frac{\partial^{2} \overline{u_{1}}}{\partial \bar{x}^{2}}\end{array}$ \\
\hline$h_{31}$ & $\left(h_{3}\right)_{x} /\left(h_{1}\right)_{x}$ & $\omega$ & Frequency of forcing function \\
\hline$h_{21}$ & $\left(h_{2}\right)_{x} /\left(h_{1}\right)_{x}$ & $\bar{\omega}$ & Non-dimensional forcing frequency \\
\hline$\left(h_{1}\right)_{x}$ & $\left(h_{1}\right)_{l}\left(1+\frac{x}{l} \alpha_{1}\right)$ & $\delta$ & Thermal gradient parameter \\
\hline$\left(h_{3}\right)_{x}$ & $\left(h_{3}\right)_{l}\left(1+\frac{x}{l} \alpha_{3}\right)$ & $\psi_{0}$ & Reference temperature \\
\hline$\left(h_{0}\right)$ & 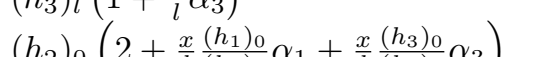 & $E_{31}$ & $E_{3} / E_{1}$ \\
\hline$I_{i}(i=1,2,3)$ & $\begin{array}{l}\left(h_{2}\right) 0\left(z+\bar{l} \overline{\left(h_{2}\right)_{0}} l_{1}+\bar{l} \overline{\left(h_{2}\right)_{0}} l_{3}\right) \\
\text { Second moments of area of cross sec- }\end{array}$ & $\lambda$ & $\begin{array}{l}\text { Coefficient of thermal expansion of } \\
\text { beam material }\end{array}$ \\
\hline & $\begin{array}{l}\text { tion about a relevant axis, } i=1 \text { for } \\
\text { top layer }\end{array}$ & $E(\xi)$ & $\begin{array}{l}\text { Variation of modulus of elasticity of } \\
\text { beam }\end{array}$ \\
\hline$l$ & Beam length & $T(\xi)$ & Distribution of elasticity modulus \\
\hline$l h_{10}$ & $l /\left(h_{1}\right)_{0}$ & $\lambda_{0}, \lambda_{1}$ & Rotation parameter \\
\hline $\bar{m}$ & Mass/unit length of beam & $\Omega_{0}$ & Uniform angular velocity of the beam \\
\hline$\overline{P_{1}}$ & $\begin{array}{l}\text { Non-dimensional amplitude for the } \\
\text { dynamic loading }\end{array}$ & $\alpha$ & $\begin{array}{l}\text { about } z^{\prime} \text { axis } \\
\frac{E_{1} A_{1}}{\Gamma}\end{array}$ \\
\hline$t$ & Time & & \\
\hline $\bar{t}$ & Non-dimensional time & & \\
\hline
\end{tabular}




\section{INTRODUCTION}

The behaviour of rotating sandwich beams is of great practical importance in the design of steam and gas turbine blades and helicopter blades. Sandwich members used vary from structural panels in aircraft to helicopter rotor blades because of their light weight and high modulus, higher strength and stiffness to weight ratio. Also, the study of sandwich structural elements of varying cross-sections has attained great importance in recent years from the economical point of view. Bhat analysed the natural frequencies and mode shapes of a rotating uniform cantilever beam with a tip mass for different values of hub radius and rotational speed by using the Rayleigh-Ritz method. ${ }^{1}$ The effect of root flexibilities and rotational speed on static buckling loads and first-order simple resonance zones of a Timoshenko beam under a periodic axial load using the finite element technique was studied by Abbas. ${ }^{2}$ Kammer and Schlack obtained the stability boundaries of a Euler beam rotating with an angular velocity, which has a small periodic component. ${ }^{3}$ The explicit stability conditions for a rotating shaft under parametric excitation comprising of a combination of stationary stochastic processes and harmonic terms using the Routh-Hurwitz criterion were derived by Sri Namachchivaya. ${ }^{4}$ Yokoyama studied the effect of an elastic foundation on static buckling loads, natural frequencies, and regions of instability of Timoshenko beams with various boundary conditions. ${ }^{5}$ The composite loss factors of laminated beams were obtained by DiTaranto and Blasingame. ${ }^{6}$ The damping effectiveness of clamped-free and hinged-hinged tapered symmetric sandwich beams were studied by Rao and Stühler. $^{7}$ Asnani and Nakra studied the vibration damping characteristics and performed a forced vibration analysis of multi-layered beams with visco-elastic cores. ${ }^{8-10}$ The flexural behaviour of a rotating non-symmetric tapered sandwich beam under linearly distributed loads was investigated by Ko. ${ }^{11} \mathrm{Kar}$ and Sujata evaluated the stability analysis of a tapered cantilever symmetric sandwich beam under a pulsating axial load and obtained the parametric instability regions. ${ }^{12}$ The effect of shear parameter, core-loss factor, and core-thickness on the regions of parametric instability of sandwich beams for various boundary conditions were investigated by Ray and Kar. ${ }^{13}$ The same authors observed the parametric instability of multilayered symmetric sandwich beams with alternate elastic and visco-elastic layers subjected to a periodic axial load. ${ }^{14}$ Ishida et al. analysed the kinds of parametric resonance and the influence of rotational speed on the unstable regions of a system consisting of a disk mounted on an elastic shaft subjected to a pulsating axial excitation. ${ }^{15}$ The dynamic stability of a rotating uniform beam subjected to a pulsating axial excitation under various boundary conditions was studied by Kar and $\mathrm{Su}-$ jata. ${ }^{16}$ The dynamic stability of a Timoshenko beam with a thermal gradient lying on variable Pasternak foundation subjected to a pulsating axial force was studied by the same authors. ${ }^{17}$ Nayak et al. investigated the stability analysis of a three-layered symmetric sandwich beam with a magnetorheological elastomer embedded visco-elastic core and conductive skins subjected to a periodic axial load under various boundary conditions. ${ }^{18}$ Tomar and Jain studied the effects of thermal gradient on the frequencies of rotating beams. ${ }^{19}$ The approxi- mate analytical expressions for the natural frequencies of nonuniform cables and beams by using the asymptotic development method was studied by Lenci et al. ${ }^{20}$ Lin and Chen studied the dynamic stability of a rotating beam with a constrained damping layer. ${ }^{21}$ The natural frequency of a non-linear rotating beam were obtained by Liu and Yeh. ${ }^{22}$ The differential equations derived by Carnegie were solved by the Ritz averaging procedure and non-linear response of a cantilever blade by Rao and Carnegie. ${ }^{23-25}$ Dash et al. studied the dynamic stability of an asymmetric sandwich beam resting on a Pasternak foundation. ${ }^{29}$ Banerjee investigated the free vibration of a sandwich beam using dynamic stiffness method. ${ }^{30}$ Caruntu reported on the non-linear bending and simultaneous resonances vibrations of non-uniform cantilever beams. ${ }^{31}$ Schilhansl determined the bending frequencies of a rotating cantilever beam. ${ }^{32}$ The differential equation of motion of a cantilever blade mounted on a rotating disc at a stager angle was obtained by Lo and Renbarger. ${ }^{33}$ The parametric instability regions of a soft and magnetorheological elastomer cored sandwich beam was investigated by Dwivedy et al. ${ }^{34}$ The linear dynamics of a two layer beam were studied by Lenci and Clementi. ${ }^{35}$ The dynamic stability of a circularly tapered rotating beam subjected to axial pulsating load and thermal gradient under various boundary conditions were investigated by Parida and Dash. ${ }^{36}$ Pradhan and Dash studied the static and dynamic stability of an asymmetric sandwich beam resting on a variable Pasternak foundation subjected to thermal gradient. ${ }^{37}$ Pradhan et. al. also investigated the stability of an asymmetric tapered sandwich beam resting on a variable Pasternak foundation subjected to a pulsating axial load with thermal gradient. ${ }^{38}$ The vibration response of functionally graded thick composite micro beams considering the effects of thermal and shear deformation was studied by Akgoz and Civalek. ${ }^{39}$ The free vibration of functionally graded Rayleigh beam was investigated by Avcar and Alwan. ${ }^{40}$ Effects of rotary inertia, shear deformation, and nonhomogeneity on frequencies of beam was studied by Avcar. ${ }^{41}$

It was found from the available literature that until now, no work has been done on the stability analysis of an asymmetric rotating tapered sandwich beam subjected to a pulsating axial load with a thermal gradient. There are many engineering applications which can be idealized as a rotating beam such as turbo engine blades, helicopter blades, and turbine blades. By using the suitable stiffness value of the spring and making the sandwich beam taper, strength can be improved with less material. Also, the effect of temperature is a vital aspect, as for most of the engineering materials, Young's modulus varies linearly with the temperature. Thus, the present work deals with the stability analysis of an asymmetric rotating tapered sandwich beam subjected to a steady one-dimensional thermal gradient under two different boundary conditions. The effects of various parameters on the non-dimensional static buckling loads and the regions of instability are studied by a computational method and the results are presented graphically. The analysis for the above system has been done as it may help the designers to design a system with a less weight to strength ratio, that is economical with better stability, and also suitable to be used at elevated temperature. 


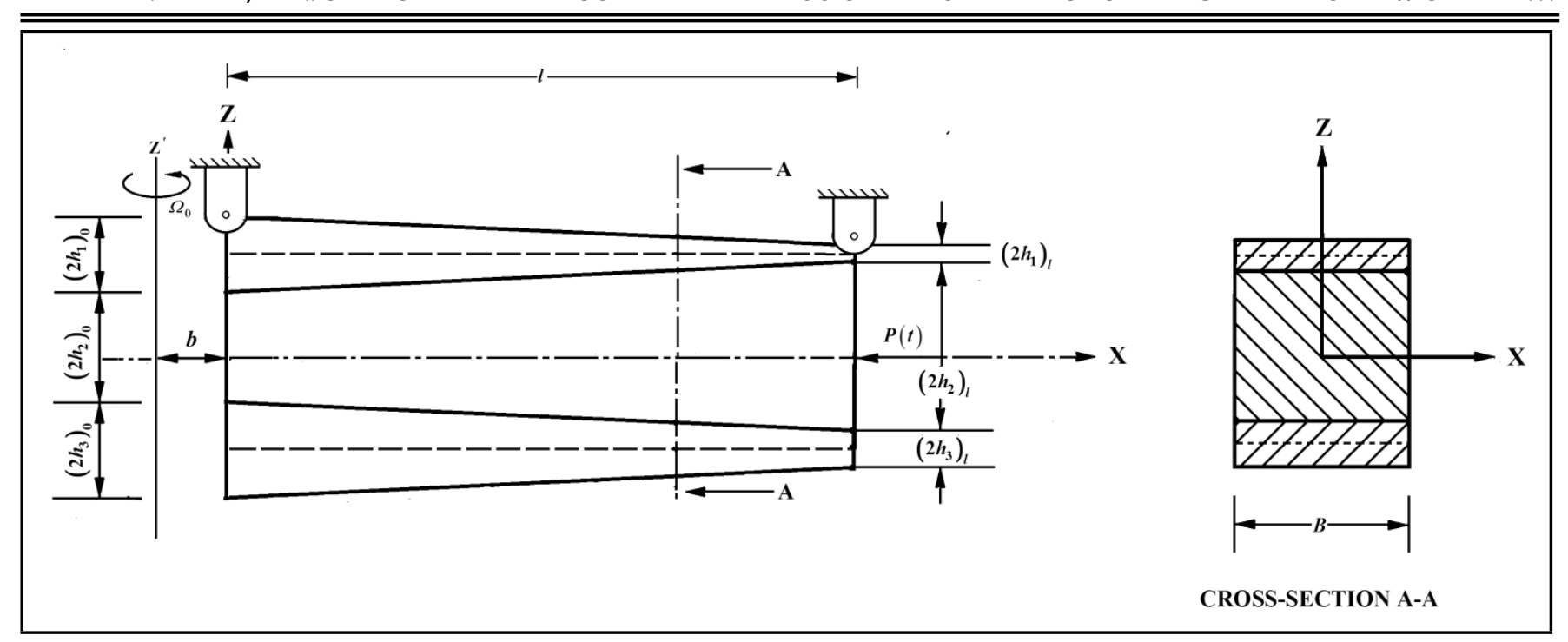

Figure 1. System configuration.

\section{FORUMLATION OF THE PROBLEM}

Figure 1 shows a rotating tapered asymmetric sandwich beam of length $l$ rotating at a uniform angular velocity of $\Omega$ about a vertical $z^{\prime}$ axis which is set at a distance $b$ from the beam and is capable of oscillating in the $x-z$ plane. The beam was subjected to a pulsating axial force $P(t)=P_{0}+$ $P_{1} \cos (\omega t)$ that acted at the end of the beam along the point of C.G. of the cross-section in the axial direction, $P_{0}$ and $P_{1}$ being the static and dynamic load amplitudes, respectively, $\omega$ being the frequency of the applied load, and $t$ being the time. The top and bottom layers were made of elastic materials with thickness, $\left(2 h_{1}\right)_{0},\left(2 h_{3}\right)_{0}$ at one end, and $\left(2 h_{1}\right)_{l},\left(2 h_{3}\right)_{l}$ at the other. The core was made of visco-elastic material with a complex shear modulus $G_{2}^{*}=G_{2}(1+j \eta)$ and had a thickness $\left(2 h_{2}\right)_{0}$ and $\left(2 h_{2}\right)_{l}$ at the ends.

The following assumptions were made for deriving the equations of motion.

1. The transverse deflection of the beam was small, and was the same everywhere in a given cross section.

2. The layers were perfectly bonded so that no slip prevails between the layers.

3. The metallic layer obeyed the Euler-Bernoulli assumption of beam theory.

4. The extensional and bending effects in the core were negligible.

5. Damping in the core was predominantly due to shear.

6. A steady one-dimensional thermal gradient was assumed to exist along the length of the beam.

7. Rotary inertia effects in the layers were negligible.

8. Kerwin's assumption was used as the force resultant in the middle visco-elastic layer and was assumed to be negligible as its Young's modulus was very small, compared to the module of the outer two layers. ${ }^{28}$ So, $E_{1} A_{1}(x) U_{1, x}+$ $E_{3} A_{3}(x) U_{3, x}=0$.
The expressions for potential energy, kinetic energy, and work done were as follows:

$$
\begin{aligned}
V= & \frac{1}{2} \int_{0}^{l} E_{1, x} A_{1, x} U_{1, x}^{2} d x+\frac{1}{2} \int_{0}^{l} E_{3, x} A_{3, x} U_{3, x}^{2} d x+ \\
& \frac{1}{2} \int_{0}^{l}\left(E_{1, x} I_{1, x}+E_{3, x} I_{3, x}\right) w_{\prime x x}^{2} d x+ \\
& \frac{1}{2} G_{2}^{*} \int_{0}^{l} A_{2, x} \gamma_{2}^{2} d x ; \\
T= & \frac{1}{2} \int_{0}^{l} \bar{m} w_{\prime_{t}}^{2} d x+\frac{1}{2} \Omega_{0}^{2} \int_{0}^{l}\left[\bar{m}(b+x) \int_{0}^{x} w_{\prime_{x}}^{2} d x\right] d x+ \\
& \frac{1}{2} \int_{0}^{l} \bar{m} \Omega_{0}^{2} w^{2} d x ; \\
w_{p}= & \frac{1}{2} \int_{0}^{l} p(t) w_{\prime x}^{2} d x
\end{aligned}
$$

where $U_{1}$ and $U_{3}$ were the axial displacements in the top and bottom layers, $w_{x}=\frac{\partial w}{\partial x}, w^{\prime} t=\frac{\partial w}{\partial t}$, and $\gamma_{2}$ was the shear strain in the middle layer as given by $\gamma_{2}=\frac{U_{1}-U_{3}}{2 h_{2}}-\frac{C w_{\prime} x}{2 h_{2}}$. $U_{3}$ was eliminated by using the Kerwin's assumption. ${ }^{28}$

The application of Hamilton's principle, $\delta \int_{t_{1}}^{t_{2}}\left(T-V+w_{p}\right) d t=0$ lead to the following nondimensional equations of motion:

$$
\begin{aligned}
& \overline{m w}^{\bar{t} \overline{t t}}+ \\
& {\left[1+\frac{\lambda_{0}^{2}\left(1+E_{31} h_{31}^{3}\right)}{\left(l h_{10}\right)^{2}\left(1+E_{31} h_{31}\right)}\left\{\frac{f}{l^{2}}-(\bar{x}+\bar{b})^{2}\right\}\right] \bar{w}^{\prime} \overline{x x x x}-} \\
& \quad \frac{2 \lambda_{0}^{2}\left(1+E_{31} h_{31}^{3}\right)}{\left(l h_{10}\right)^{2}\left(1+E_{31} h_{31}\right)}(\bar{x}+\bar{b}) \bar{w}^{\prime} \overline{x x x}+ \\
& {\left[\frac{\lambda_{0}^{2}\left(1+E_{31} h_{31}^{3}\right)}{\left(l h_{10}\right)^{2}\left(1+E_{31} h_{31}\right)}-\lambda_{0}^{2}\left\{\frac{f}{l^{2}}-(\bar{x}+\bar{b})^{2}\right\}-\right.}
\end{aligned}
$$




$$
\begin{aligned}
& \left.3 g^{*}\left(1+\frac{h_{12}+h_{32}}{2}\right)^{2}+\bar{p}(\bar{t})\right] \bar{w} ' \overline{x x}+\lambda_{0}^{2}(\bar{x}+\bar{b}) \bar{w}^{\prime} \bar{x}+ \\
& \frac{3}{2} g^{*} l h_{10} h_{12}\left(1+\frac{h_{12}+h_{32}}{2}\right)(1+\alpha) \frac{2\left(h_{2}\right)_{0}}{C} \gamma_{2^{\prime}}=0 \\
& \frac{2\left(h_{2}\right)_{0}}{C} \gamma_{2^{\prime} \overline{x x}}- \\
& \frac{g^{*}}{4} h_{12}^{2}\left(\frac{1+E_{31} h_{31}^{3}}{1+\alpha^{2} E_{31} h_{31}}\right)(1+\alpha)\left[(1+\alpha) \frac{2\left(h_{2}\right)_{0}}{C} \gamma_{2}-\right. \\
& \left.\left(\frac{2\left(1+\left(h_{12}+h_{32}\right) / 2\right)}{\left(l h_{10} h_{12}\right)}\right) \bar{w}^{\prime} \bar{x}\right]=0 .
\end{aligned}
$$

In the above: $\bar{w}^{\prime} \overline{x x x x}=\frac{\partial^{4} \bar{w}}{\partial \bar{x}^{4}}, \bar{w}^{\prime} \overline{x x}=\frac{\partial^{2} \bar{w}}{\partial \bar{x}^{2}}, \gamma_{2^{\prime} \overline{x x x}}=\frac{\partial^{3} \gamma_{2}}{\partial \bar{x}^{3}}$, $\gamma_{2^{\prime} \overline{x x}}=\frac{\partial^{2} \gamma_{2}}{\partial \bar{x}^{2}}, \bar{x}=\frac{x}{l}, \bar{U}=\frac{U}{l}, \bar{w}=\frac{w}{l}, \bar{t}=\frac{t}{t_{0}}, C=$ $\left(h_{1}\right)_{l}+\left(2 h_{2}\right)_{l}+\left(h_{3}\right)_{l}, t_{0}=\left[\frac{\rho_{1} A_{10} l^{4}}{E_{1}\left(I_{1}\right)_{0}}\right]^{1 / 2}, \bar{P}_{0}=\frac{P_{0} l^{2}}{E_{1}\left(I_{1}\right)_{0}}$, $\bar{P}_{1}=\frac{P_{1} l^{2}}{E_{1}\left(I_{1}\right)_{0}}, \bar{P}=\bar{P}_{0}+\bar{P}_{1} \cos (\bar{\omega} \bar{t}), \bar{\omega}=\omega t_{0}$. The various section dependent parameters were:

$$
\begin{aligned}
\bar{m} & =(1-\bar{x})+ \\
& \bar{x}\left(\frac{\left(h_{1}\right)_{l}}{\left(h_{1}\right)_{0}}\right)\left(\frac{\rho_{2}}{\rho_{1}}\right)\left(\frac{\left(h_{2}\right)_{0}}{\left(h_{1}\right)_{0}}(1-\bar{x})\left(\frac{\rho_{3}}{\rho_{1}}\right) \frac{\left(h_{3}\right)_{0}}{\left(h_{1}\right)_{0}}\right)(1-\bar{x})+ \\
& \bar{x}\left(\frac{\left(h_{2}\right)_{l}}{\left(h_{1}\right)_{0}}\right)\left(\frac{\rho_{2}}{\rho_{1}}\right)+\left(\frac{\left(h_{3}\right)_{1}}{\left(h_{1}\right)_{0}}\right)\left(\frac{\rho_{3}}{\rho_{1}}\right) \bar{x} \\
g^{*} & =\frac{G_{2}^{*} h_{21}\left(l h_{10}\right)^{2}}{E_{1, x}\left(1+E_{31} h_{31}^{3}\right)} .
\end{aligned}
$$

The associated boundary conditions at $\bar{x}=0$ and $\bar{x}=1$ were:

$$
\begin{gathered}
{\left[1+\frac{\lambda_{0}^{2}\left(1+E_{31} h_{31}^{3}\right)}{\left(l h_{10}\right)^{2}\left(1+E_{31} h_{31}\right)}\left\{\frac{f}{l^{2}}-(\bar{x}+\bar{b})^{2}\right\}\right] \bar{w}, \overline{x x x}-} \\
\quad \frac{2 \lambda_{0}^{2}\left(1+E_{31} h_{31}^{3}\right)}{\left(l h_{10}\right)^{2}\left(1+E_{31} h_{31}\right)}(\bar{x}+\bar{b}) \bar{w}, \overline{x x}
\end{gathered}
$$

2 or

$$
\begin{aligned}
& \bar{w}^{\prime} \bar{x}=0 ; \\
& {\left[\frac{\lambda_{0}^{2}\left(1+E_{31} h_{31}^{3}\right)}{\left(l_{10}\right)^{2}\left(1+E_{31} h_{31}\right)}-\lambda_{0}^{2}\left\{\frac{f}{l^{2}}-(\bar{x}+\bar{b})^{2}\right\}-\right.} \\
& \left.3 g^{*}\left(1+\frac{h_{12}+h_{32}}{2}\right)^{2}+\bar{p}(\bar{t})\right] \bar{w}^{\prime} \bar{x}=0 ;
\end{aligned}
$$

or

$$
\begin{aligned}
& \bar{w}=0 ; \\
& \frac{3}{2} g^{*} l h_{10} h_{12}\left(1+\frac{h_{12}+h_{32}}{2}\right)(1+\alpha) \frac{2\left(h_{2}\right)_{0}}{C} \gamma_{2^{\prime}} \bar{x}=0 ;
\end{aligned}
$$

or

$$
\gamma_{2}=0 .
$$

\subsection{Approximate Solution}

The solutions of Eqs. (1) and (2) were assumed in the form:

$$
\begin{aligned}
\bar{w}(\bar{x}, \bar{t}) & =\sum_{i=1}^{i=p} w_{i}(\bar{x}) f_{i}(\bar{t}) \\
\bar{\gamma}_{2}(\bar{x}, \bar{t}) & =\sum_{k=p+1}^{k=2 p} \gamma_{k}(\bar{x}) f_{k}(\bar{t}) .
\end{aligned}
$$

Here $w_{i}$ and $\gamma_{k}$ were the shape functions and $f_{i}$ and $f_{k}$ were the generalized coordinates. The sets $w_{i}$ and $\gamma_{k}$ were chosen as to satisfy as many boundary conditions as possible. ${ }^{26}$ The shape functions used for the different boundary conditions were same as that of Ray and Kar. ${ }^{13}$

1. For a pinned-pinned (P-P) case: $w_{i}(\bar{x})=\sin (i \pi \bar{x}), \gamma_{k}(\bar{x})=\cos (k \pi \bar{x})$.

2. For a clamped-pinned (C-P) case:

$$
\begin{aligned}
& w_{i}(\bar{x})=2(i+2) \bar{x}^{(i+1)}-(4 i+6) \bar{x}^{(i+2)}+2(i+1) \bar{x}^{(i+3)}, \\
& \gamma_{\bar{k}}(\bar{x})=(\bar{k}+1) \bar{x}^{\bar{k}}-\bar{k} \bar{x}^{(\bar{k}+1)}, \text { where } \bar{k}=k-p .
\end{aligned}
$$

Substituting the above equations in Eqs. (1) and (2) and the use of the general Galerkin method yielded the following matrix equations of motion in the generalized coordinates. Moreover, five-term approximations were used for the series of solutions in next simulations:

$$
\begin{aligned}
{[m]\left\{\ddot{Q}_{i}\right\}+\left[k_{11}\right]\left\{Q_{1}\right\}+\left[k_{12}\right]\left\{Q_{2}\right\} } & =\{0\} ; \\
{\left[k_{21}\right]\left\{Q_{1}\right\}+\left[k_{22}\right]\left\{Q_{2}\right\} } & =\{0\} ;
\end{aligned}
$$

where

$$
\begin{aligned}
\left\{Q_{1}\right\}= & \left\{f_{1}, \ldots, f_{p}\right\}^{T} \\
\left\{Q_{2}\right\}= & \left\{f_{p+1}, \ldots, f_{2 p}\right\}^{T} \\
m_{i j}= & \int_{0}^{1} \bar{m} w_{i} w_{j} d \bar{x} ; \\
k_{11 i j}= & \int_{0}^{1}\left[1+\lambda_{1}\left\{\frac{f}{l^{2}}-(\bar{x}+\bar{b})^{2}\right\}\right] w_{i}^{\prime \prime} w_{j}^{\prime \prime} d \bar{x}+ \\
& \lambda_{0}^{2} \int_{0}^{1}\left\{\frac{f}{l^{2}}-(\bar{x}+\bar{b})^{2}\right\} w_{i}^{\prime} w_{j}^{\prime} d \bar{x}+ \\
& \left\{3 g^{*}\left(1+\frac{h_{12}+h_{32}}{2}\right)^{2}-\bar{p}(\bar{t})\right\} \int_{0}^{1} w_{i}^{\prime} w_{j}^{\prime} d \bar{x} ; \\
& -\frac{3}{2} g^{*} l h_{10} h_{12}(1+\alpha)\left(1+\frac{h_{12}+h_{32}}{2}\right)\left(\int_{0}^{1} u_{l} w_{i}^{\prime} d \bar{x}\right) ;
\end{aligned}
$$

$$
\begin{aligned}
k_{22 k l}= & 3 \times\left(l h_{10}\right)^{2} \frac{\left(1+\alpha^{2} E_{31} h_{31}\right)}{\left(1+E_{31} h_{31}^{3}\right)}\left(\int_{0}^{1} u_{k}^{\prime} u_{l}^{\prime} d \bar{x}\right)+ \\
& \frac{3}{4} g^{*}\left(l h_{10}\right)^{2} h_{12}^{2}(1+\alpha)^{2}\left(\int_{0}^{1} u_{k} u_{l} d \bar{x}\right) .
\end{aligned}
$$


In the above, $u_{k}=\frac{2 h_{2}}{C} \gamma_{k}, u_{l}=\frac{2 h_{2}}{C} \gamma_{l}$ and $w_{i}^{\prime}=\frac{\partial w_{i}}{\partial x}$, $f= \begin{cases}(l+b)^{2}, & \text { for } x=l \\ b^{2}, & \text { for } x=0 \quad ;\left[k_{21}\right]=\left[k_{12}\right]^{T} . \\ \frac{l^{2}}{3}+b^{2}+b l, & \text { for other cases }\end{cases}$

The Eqs. (11) and (12) were further simplified to:

$$
\begin{gathered}
{[m]\left\{\ddot{Q}_{1}\right\}+\left[[k]-\bar{P}_{0}[H]\right]\left\{Q_{1}\right\}-} \\
\bar{P}_{1} \cos (\bar{\omega} \bar{t})[H]\left\{Q_{1}\right\}=\{0\}
\end{gathered}
$$

where

$$
\begin{aligned}
{[k]=} & {[\bar{k}]-\left[k_{12}\right]\left[k_{22}\right]^{-1}\left[k_{12}\right]^{T} ; } \\
H_{i j}= & \int_{0}^{1} w_{i}^{\prime} w_{j}^{\prime} d \bar{x} \\
{[\bar{k}]_{i j}=} & \int_{0}^{1}\left[1+\lambda_{1}\left\{\frac{f}{l^{2}}-(\bar{x}+\bar{b})^{2}\right\}\right] w_{i}^{\prime \prime} w_{j}^{\prime \prime} d \bar{x}+ \\
& \lambda_{0}^{2} \int_{0}^{1}\left\{\frac{f}{l^{2}}-(\bar{x}+\bar{b})^{2}\right\} w_{i}^{\prime} w_{j}^{\prime} d \bar{x}+ \\
& \left\{3 g^{*}\left(1+\frac{h_{12}+h_{32}}{2}\right)^{2}\right\} \int_{0}^{1} w_{i}^{\prime} w_{j}^{\prime} d \bar{x} .
\end{aligned}
$$

\subsection{Static Buckling Loads}

The substitution of $\bar{P}_{1}=0$ and $\left\{\ddot{Q}_{1}\right\}=0$ into Eq. (19) lead to the eigenvalue problem $[k]^{-1}[H]\left\{Q_{1}\right\}=\frac{1}{P_{0}}\left\{Q_{1}\right\}$. The static buckling loads $\left(P_{0}\right)_{\text {crit }}$ for the first few modes were obtained as the real parts of the reciprocals of the eigenvalues of $[k]^{-1}[H]$.

\subsection{Parametric Instability}

Referring to Saito and Otomi, the following equations were derived: ${ }^{27}$

$$
\begin{gathered}
U_{N}+\omega_{N}^{* 2} U_{N}+2 \varepsilon \cos \bar{\omega} \bar{t} \sum_{M=1}^{M=p} b_{N M} U_{M}=0 \\
N=1,2, \ldots, P
\end{gathered}
$$

where $b_{N M}$ were the elements of $[B], \omega_{N}^{*}$ were the distinct eigenvalues of the system, $\varepsilon=\frac{\bar{P}_{1}}{2}<1$ and $[B]=-[L]^{-1}[M]^{-1}[H][L],[L]$ was the modal matrix of $[M]^{-1}\left[[k]-\bar{P}_{0}[H]\right]$.

So, $\left\{Q_{1}\right\}=[L]\{U\}$ where $\{U\}$ was a new set of generalized co-ordinates. For subsequent usages,

$$
\begin{aligned}
\omega_{N}^{*} & =\omega_{N, R}+j \omega_{N, I} ; \\
b_{N M} & =b_{N M, R}+j b_{N M, I} \\
\mu, \nu & =1,2, \ldots, N .
\end{aligned}
$$

The boundaries of the region of instability of main and combination resonances were obtained using the following conditions by Saito and Otomi. ${ }^{27}$

\subsubsection{Case $(A)$ main resonance}

In this case, the regions of instability were given by

$$
\left|\frac{\bar{\omega}}{2}-\bar{\omega}_{\mu, R}\right|<\frac{1}{4} \sqrt{\left(\frac{\bar{P}_{1}^{2}\left(b_{\mu \mu, R}^{2}+b_{\mu \mu, I}^{2}\right)}{\bar{\omega}_{\mu, R}^{2}}-16 \bar{\omega}_{\mu, I}^{2}\right)}
$$

when damping was present and

$$
\left|\frac{\bar{\omega}}{2}-\bar{\omega}_{\mu, R}\right|<\frac{1}{4}\left|\frac{\bar{P}_{1} b_{\mu \mu, R}}{\bar{\omega}_{\mu, R}}\right| ;
$$

for the un-damped case, $\mu=1,2, \ldots, N$.

\subsubsection{Case (B) combination resonance of sum type}

This type of resonance occurred when $\mu>\nu,(\mu, \nu=$ $1,2, \ldots, N)$, and the regions of instability were given by

$$
\begin{aligned}
\left|\frac{\bar{\omega}}{2}-\frac{1}{2}\left(\bar{\omega}_{\mu, R}+\bar{\omega}_{\nu, R}\right)\right|<\frac{\bar{\omega}_{\mu, I}+\bar{\omega}_{\nu, I}}{8 \sqrt{\bar{\omega}_{\mu, I} \bar{\omega}_{\nu, I}}} \cdot \\
\quad \sqrt{\frac{\bar{P}_{1}^{2}}{\bar{\omega}_{\mu, R} \bar{\omega}_{\nu, R}}\left(b_{\mu \nu, R} b_{\nu \mu, R}+b_{\nu \mu, I} b_{\mu \nu, I}\right)-16 \bar{\omega}_{\mu, I} \bar{\omega}_{\nu, I}}
\end{aligned}
$$

for the damped case and

$$
\left|\frac{\bar{\omega}}{2}-\frac{1}{2}\left(\bar{\omega}_{\mu, R}+\bar{\omega}_{\nu, R}\right)\right|<\frac{\bar{P}_{1}}{4} \sqrt{\frac{b_{\mu \nu, R} b_{\nu \mu, R}}{\bar{\omega}_{\mu, R} \bar{\omega}_{\nu, R}}}
$$

for un-damped case.

\subsubsection{Case (C) combination resonance of the differ- ence type}

This type of resonance occurred when $\mu<\nu,(\mu, \nu=$ $1,2, \ldots, N)$, and the regions of instability are given by

$$
\begin{aligned}
\left|\frac{\bar{\omega}}{2}-\frac{1}{2}\left(\bar{\omega}_{\nu, R}-\bar{\omega}_{\mu, R}\right)\right|<\frac{\bar{\omega}_{\mu, I}+\bar{\omega}_{\nu, I}}{8 \sqrt{\bar{\omega}_{\mu, I}+\bar{\omega}_{\nu, I}}} \cdot \\
\quad \sqrt{\frac{\bar{P}_{1}^{2}}{\bar{\omega}_{\mu, R} \bar{\omega}_{\nu, R}}\left(-b_{\mu \nu, R} b_{\nu \mu, R}+b_{\mu \nu, I} b_{\nu \mu}-16 \bar{\omega}_{\mu, I} \bar{\omega}_{\nu, I}\right)}
\end{aligned}
$$

for damped case and

$$
\left|\frac{\bar{\omega}}{2}-\frac{1}{2}\left(\bar{\omega}_{\nu, R}-\bar{\omega}_{\mu, R}\right)\right|<\frac{\bar{P}_{1}}{4} \sqrt{\frac{-b_{\mu \nu, R} b_{\nu \mu, R}}{\bar{\omega}_{\mu, R} \bar{\omega}_{\mu, R}}} ;
$$

for un-damped case.

\section{NUMERICAL RESULTS AND DISCUSSION}

Numerical results are obtained for various values of the parameters such as the shear parameter, core loss factor, hub radius, rotation parameter, core-density parameter, thermal gradient, and taper parameters and were presented graphically. Some of the figures are essentially similar to the ones presented, and thus those findings are explained without figures. 


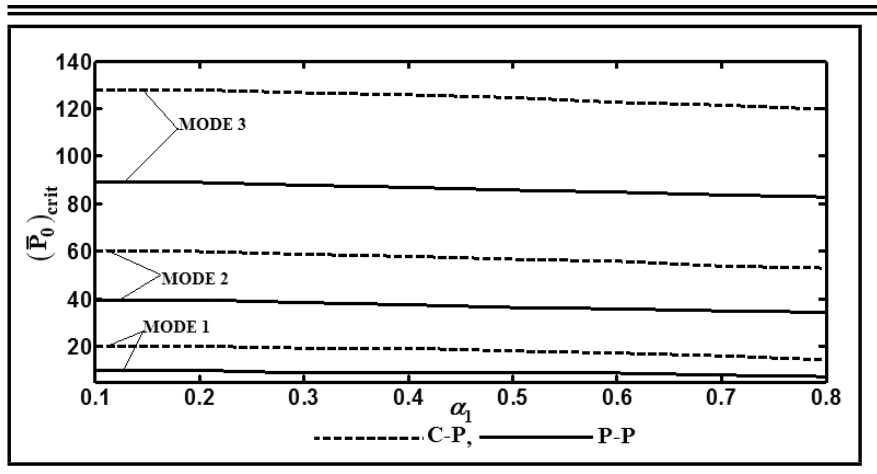

Figure 2. Variation of $\left(\bar{P}_{0}\right)_{\text {crit }}$ with $\alpha_{1}$.

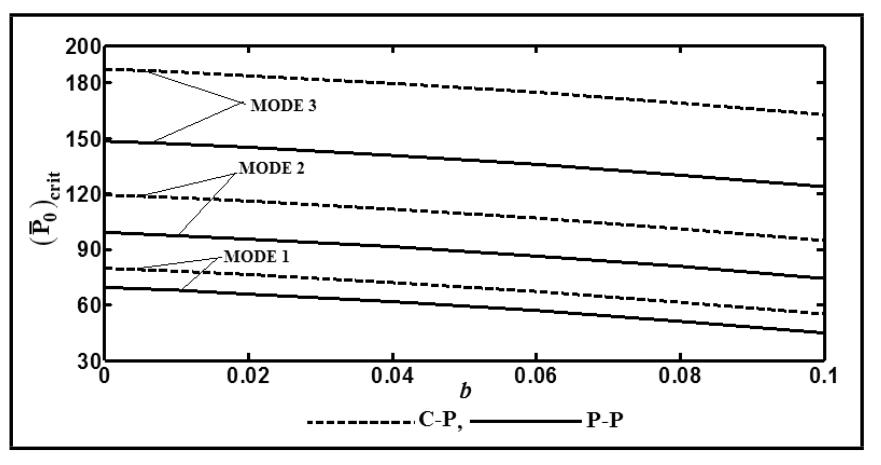

Figure 3. Variation of $\left(\bar{P}_{0}\right)_{\text {crit }}$ with $b$.

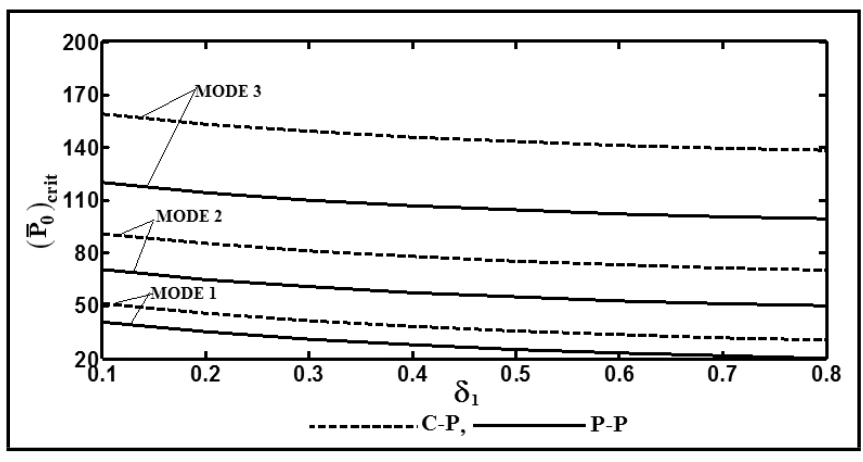

Figure 4. Variation of $\left(\bar{P}_{0}\right)_{\text {crit }}$ with $\delta_{1}$.

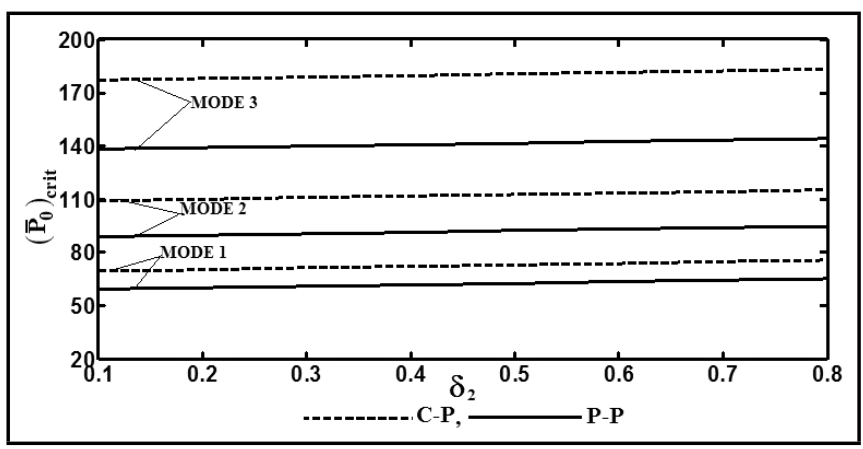

Figure 5. Variation of $\left(\bar{P}_{0}\right)_{\text {crit }}$ with $\delta_{2}$.

This is done to keep the number of figures to a minimum. For relevant values of the parameters, considering the configuration of a uniform rotating beam and neglecting thermal gradient the equation of motions will be reduced to what was shown in Kar and Sujata, and a good agreement is observed. ${ }^{16}$

The temperature above the reference temperature at any point $\xi$ from the end of the beam is assumed to be $\psi=$ $\psi_{0}(1-\xi)$. Choosing $\psi=\psi_{0}$, the temperature at the end $\xi=1$ as the reference temperature, the variation of modulus of elasticity of the beam, Kar and Sujata is denoted by: ${ }^{17}$

$$
E(\xi)=E_{1}\left[1-\lambda \psi_{1}(1-\xi)\right]=E_{1} T(\xi) ; \quad 0 \leq \lambda \psi_{1}<1 ;
$$

where $\lambda$ is the coefficient of thermal expansion of the beam material, $\delta=\lambda \psi_{1}$ is the thermal gradient parameter, and $T(\xi)=[1-\delta(1-\xi)]$.

Here we are considering:

$$
\alpha=\frac{E_{1} A_{1}}{E_{3} A_{3}}=\frac{E_{1} T(\xi) A_{1}}{E_{3} T(\xi) A_{3}}=\frac{E_{1} A_{1}\left[1-\delta_{1}(1-\xi)\right]}{E_{3} A_{3}\left[1-\delta_{2}(1-\xi)\right]} ;
$$

where $\delta_{1}$ and $\delta_{2}$ are thermal gradient in the top and bottom layer, respectively. The values of the various parameters used, unless stated otherwise, are as follows $\eta=0.01, b=0.05$, $g=0.1, \lambda_{0}=0.05, \lambda_{1}=0.1, \delta_{1}=0.1, \delta_{2}=0.2$ and $P_{0}=0.05$. Figures 2 to 14 show the effect of various system parameters on the non-dimensional static buckling loads.

\subsection{Static Figures}

Figure 2 displays the effect of $\alpha_{1}$ on the static buckling loads. With an increase in the value of $\alpha_{1}$, the static buckling loads decrease for all the three modes for both the considered boundary conditions.

The effect of $b$ on the static buckling loads is shown in Fig. 3. The static buckling loads decrease with an increase in the value of $b$ and the variation is non-linear in nature. Thus, larger values of $b$ have a destabilizing effect on the system.

Figures 4 and 5 display the effect of $\delta_{1}$ and $\delta_{2}$ on the static buckling loads. With an increase in the value of $\delta_{1}$, the static buckling load decreases, while, with an increase in the value of $\delta_{2}$, the static buckling load increases for all the considered cases.

The effect of variation of $g$ on the static buckling loads is addressed in Fig. 6. The larger values of $g$ are desirable as the static buckling load increases with an increase in the value of $g$.

The effect of $\mu_{1}$ on the static buckling loads is shown in Fig. 7. The static buckling loads remain almost independent of the parameter $\mu_{1}$.

Figure 8 depicts the effect of $\lambda_{0}$ on the static buckling loads. For all the considered cases, the static buckling load increases non-linearly with an increase in the value of $\lambda_{0}$.

The effects of $\alpha_{3}, \mu_{2}$, and $\lambda_{1}$ on the static buckling loads are similar to that of $\alpha_{1}, \mu_{1}$, and $\lambda_{0}$, respectively, so those graphs are not shown here. Also, the static buckling loads are independent of $\eta$, which is obvious. Hence, the graph is not provided here.

\subsection{Dynamic Figures}

\subsubsection{Pinned-pinned (P-P) case}

Figures 9 to 15 show the effects of various parameters on the regions of instability of the system for a P-P case.

As shown in Fig. 9, the dynamic stability of the system decreases with an increase in the value of $b$, as all the resonance zones are shifted towards lower excitation frequencies with an increase in the value of $b$ from 0 to 0.1 . 


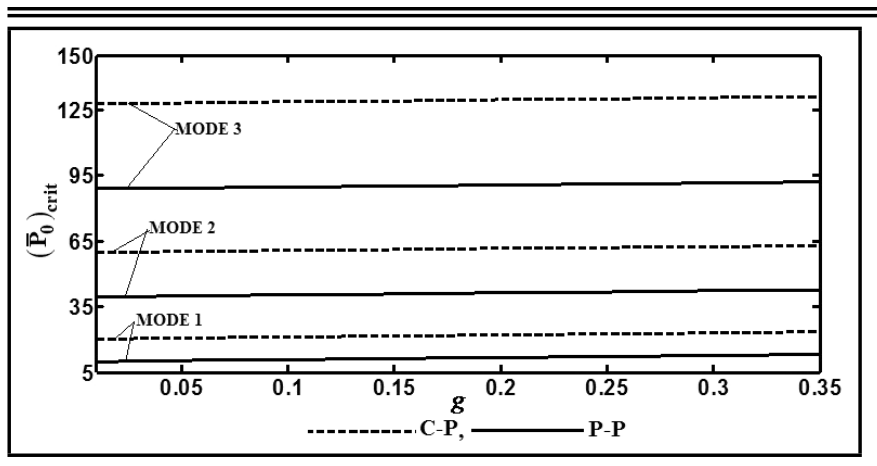

Figure 6. Variation of $\left(\bar{P}_{0}\right)_{\text {crit }}$ with $g$.

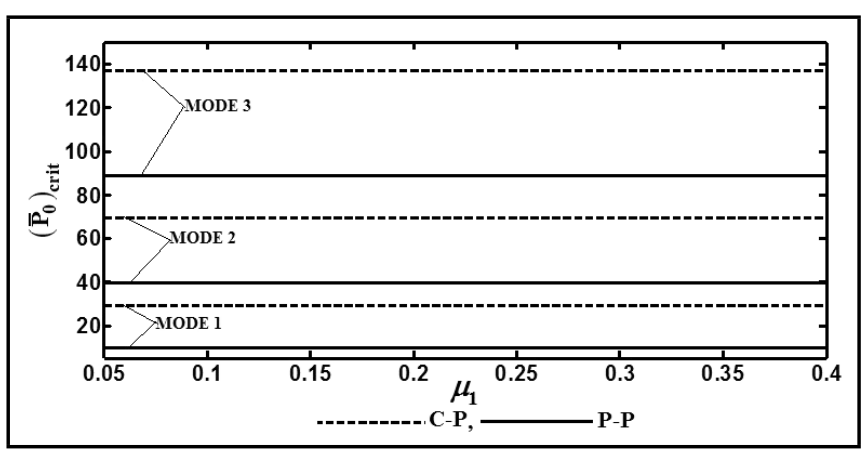

Figure 7. Variation of $\left(\bar{P}_{0}\right)_{\text {crit }}$ with $\mu_{1}$

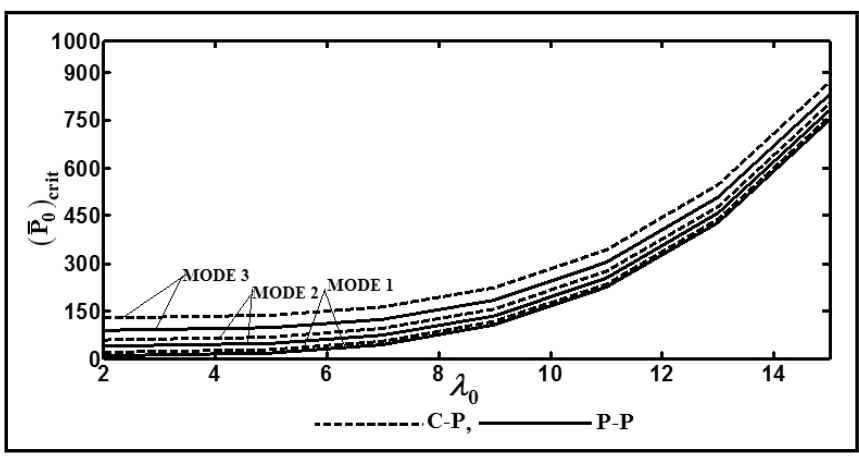

Figure 8. Variation of $\left(\bar{P}_{0}\right)_{\text {crit }}$ with $\lambda_{0}$.

The stability diagram for different values of $\delta_{1}$ is shown in Fig. 10. From the figure, it is seen that with an increase in the value of $\delta_{1}$, all the resonance zones are shifted towards lower excitation frequencies, thus indicating a destabilization of the system.

The effect of $\delta_{2}$ on the regions of instability is shown in Fig. 11. The set $\delta_{2}$ improves the system stability as all the instability zones are shifted towards higher excitation frequencies for the larger values of $\delta_{2}$.

Figure 12 addresses the effect of $g$ on the zones of instability. With an increase in the value of $g$, all the instability zones are shifted towards higher excitation frequencies, moving upward and reducing the area of the zones creating a destabilization of the system.

The effect of $\mu_{1}$ on the dynamic stability of the system is shown in Fig. 13. The set $\mu_{1}$ has a destabilizing effect as all the resonance zones are shifted towards lower excitation frequencies with an increase in the value of $\mu_{1}$ from 0.05 to 0.5 .

Figure 14 shows the effect of $\lambda_{0}$ on the instability regions of the system. With an increase in the value of $\lambda_{0}$, all the instability regions are shifted towards higher excitation frequencies, thus indicating a stabilization of the system.

Figure 15 depicts the effect of $\eta$ on the instability zones of the system. With an increase in the value of $\eta$, the stability of the system improves by reducing the vibration, which is obvious.

The effect of variation of $\alpha_{1}$ on the regions of instability is shown in Fig. 16. With an increase in the value of $\alpha_{1}$, all the resonance zones are shifted slightly towards lower excitation frequencies, indicating a destabilization of the system. Due to a very marginal effect, the variation is not clearly visible from the graph.

\subsubsection{Clamped-pinned (C-P) case}

The effects of an increase in the value of $\alpha_{1}$ from -0.4 to 0.5 for $g=0.01, \lambda_{0}=5, b=0.05$, and $\eta=0.1$ are shown in Figs. 17 and 18. All the resonance zones are shifted towards lower excitation frequencies for $\alpha_{1}=0.5$. Thus, the taper parameter has a destabilization effect on the stability of the system.

The stability diagrams for two different values of $\delta_{1}$ with $g=0.01, \lambda_{0}=5, b=0.05$, and $\eta=0.1$ are shown in Figs. 19 and 20. The simple, as well as combination, resonance zones are shifted towards lower excitation frequencies with an increase in the value of $\delta_{1}$ from 0.2 to 0.8 . So, $\delta_{1}$ has a destabilizing effect on the system.

Figures 21 and 22 depict the effect of $\delta_{2}$ with $g=0.01$, $\lambda_{0}=5, b=0.05$, and $\eta=0.1$. With an increase in the value of $\delta_{2}$ from 0.2 to 0.8 , the resonance zones are shifted towards higher excitation frequencies, hence there is a stabilization of the system.

The effect of an increase in the value of $b$ from 0.05 to 0.1 with $g=0.01, \lambda_{0}=5$, and $\eta=0.1$ on the instability regions are shown in Figs. 23 and 24. All the instability regions that shifted towards lower excitation frequencies became wider in Fig. 24, in comparison to Fig. 23. So, $b$ has a destabilizing effect on the system.

Figures 25 and 26 address the instability zones for $g=0.05$ and 0.1 , with $\lambda_{0}=5, b=0.05$, and $\eta=0.1$. With a change in the value of $g$ from 0.05 to 0.1 , that shifts all the resonance zones slightly towards higher excitation frequencies and they move in an upward direction with reduced areas, thus there is a stabilization of the system.

The stability diagrams for $\mu_{1}=0.05$ and 0.5 with $\eta=0.1$, $g=0.01$, and $\lambda_{0}=5$ are shown in Figs. 27 and 28, respectively. From the figures, it is clear that with an increase in the value of $\mu_{1}$ from 0.05 to 0.5 , the instability zones shift towards lower excitation frequencies, keeping the vertical positions unchanged, thus indicating destabilization.

With an increase in the value of $\eta$ from 0.01 to 0.1 , with $g=0.01, \lambda_{0}=5$, and $b=0.05$, that shifts all the resonance zones slightly towards the right, as shown in Figs. 29 and 30. So, $\eta$ has a stabilizing effect on the system.

The stability diagrams for $\lambda_{0}=5$ and 10 , with $\eta=0.1$, $g=0.01$, and $b=0.05$ are shown in Figs. 31 and 32. With an increase in the value of $\lambda_{0}$ from 5 to 10 , the instability zones shift towards higher excitation frequencies and became narrower, and thus improve the stability of the system. 


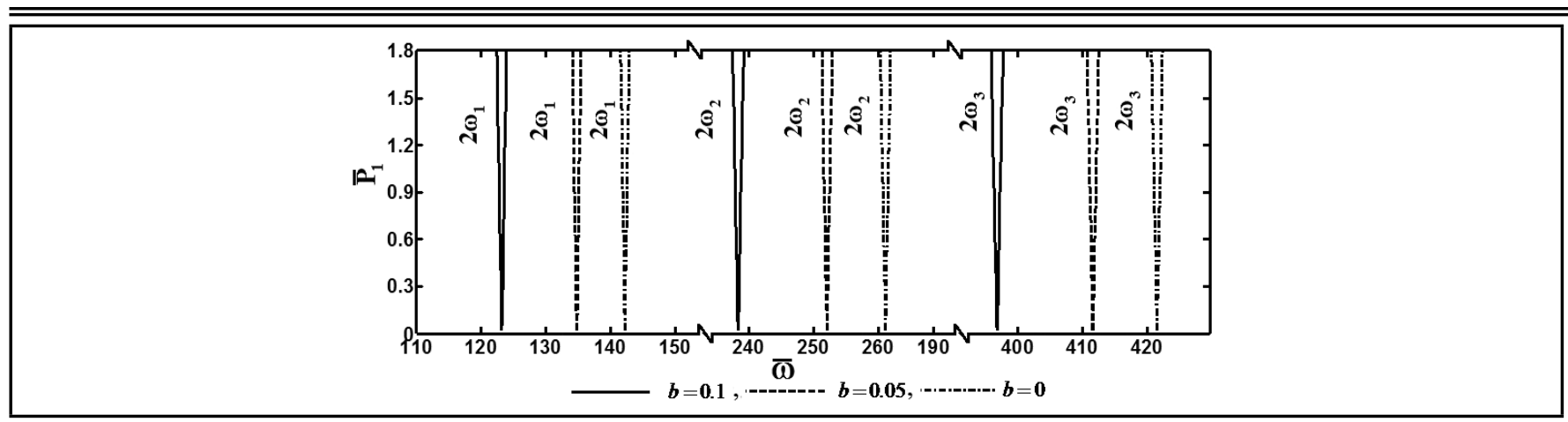

Figure 9. Effect of $b$ on the instability zones.

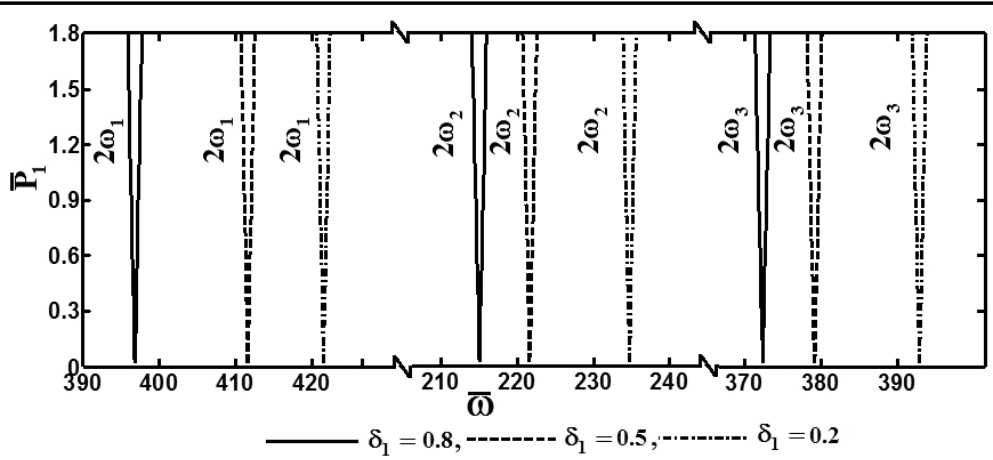

Figure 10. Effect of $\delta_{1}$ on the instability zones.

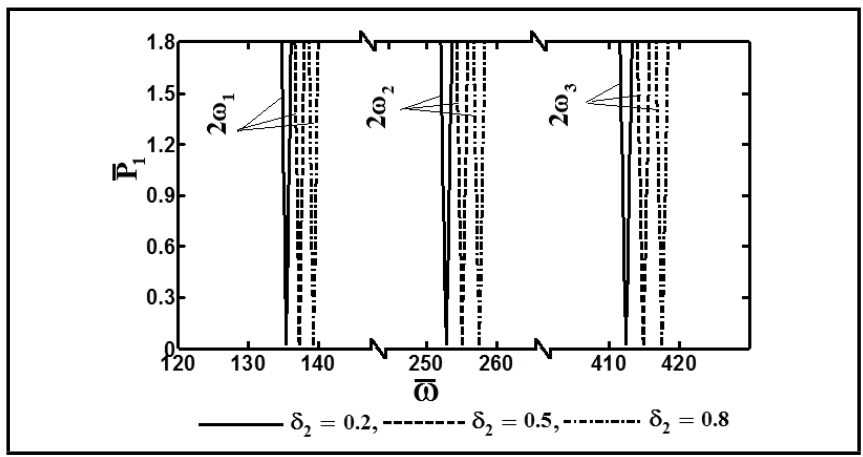

Figure 11. Effect of $\delta_{2}$ on the instability zones.

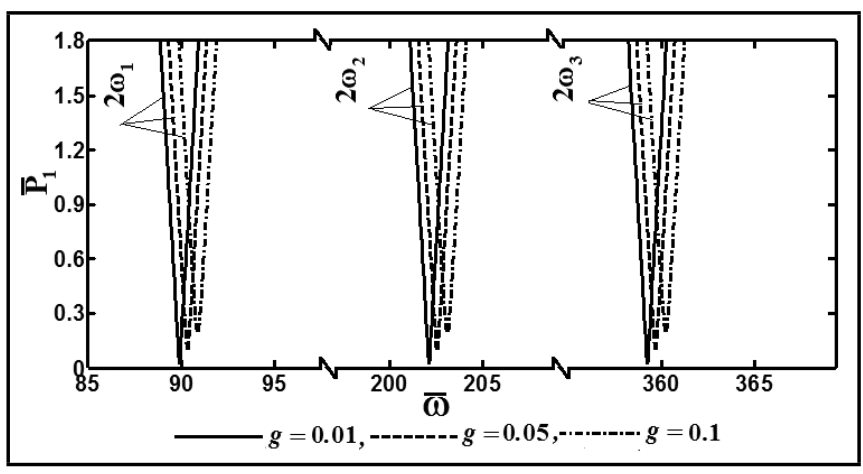

Figure 12. Effect of $g$ on the instability zones.

\section{CONCLUSIONS}

The static and dynamic stability of an asymmetric rotating tapered sandwich beam subjected to a pulsating axial load with thermal gradient is investigated under P-P and C-P end conditions.

The results reveal that, while an increase in the values of $g$, $\lambda_{0}$, and $\delta_{2}$ increases the static buckling loads, an increase in the values of $\alpha_{1}, \alpha_{3}, \delta_{1}$, and $b$ have the reverse effect. The static buckling loads are independent of $\eta, \mu_{1}$, and $\mu_{2}$. The dynamic stability of the system improves with an increase in the value of $g, \lambda_{0}, \delta_{2}$, and $\mu$. A further increase in the values of $\alpha_{1}, \alpha_{3}, \delta_{1}$, $b, \mu_{1}$, and $\mu_{2}$ worsen the dynamic stability of the system. With an increase in the values of $\lambda_{0}$, both static and dynamic stability of the system are improved, as it gives a stretching inward force to the system. For the larger values of $g$, more tangential force arises, which helps in reducing the amplitude of vibration of the system and stabilization of the system. The thermal gradient for the top layer, hub radius, core-density parameters, and taper parameters reduce the rigidity of the system and hence worsen the stability of the system. But the thermal gradient for the bottom layer improves the rigidity and stability of the system. Combination resonances of sum type occur for a C$\mathrm{P}$ case, whereas only simple resonances occur for a P-P case. Further, it is found that a C-P case is more stable than a P-P case.

\section{REFERENCES}

1 Bhat, R. B. Transverse vibrations of a rotating uniform cantilever beam with tip mass as predicted by using beam characteristic orthogonal polynomials in the Rayleigh-Ritz method, Journal of Sound and Vibration, 105 (2), 199-210, (1986). https://dx.doi.org/10.1016/0022-460X(86)90149-5

2 Abbas, B. A. H. Dynamic stability of a rotating Timoshenko beam with a flexible root, Journal of Sound and Vibration, 108 (1), 25-32, (1986). https://dx.doi.org/10.1016/S0022460X(86)80308-X

3 Kammer, D. C. and Schlack, A. L. Dynamic response 


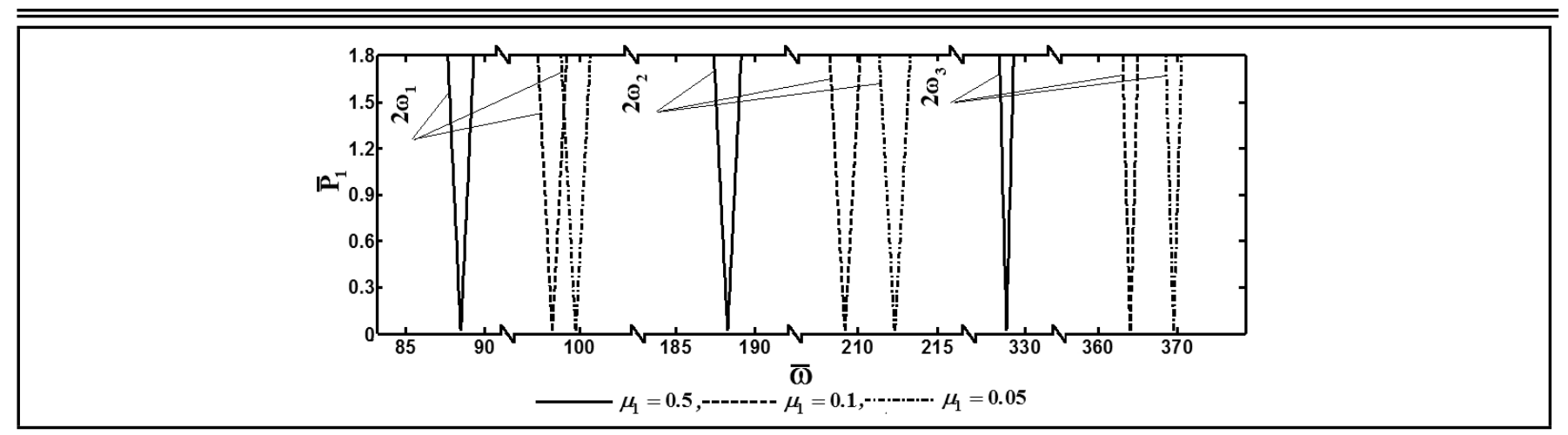

Figure 13. Effect of $\mu_{1}$ on the instability zones.

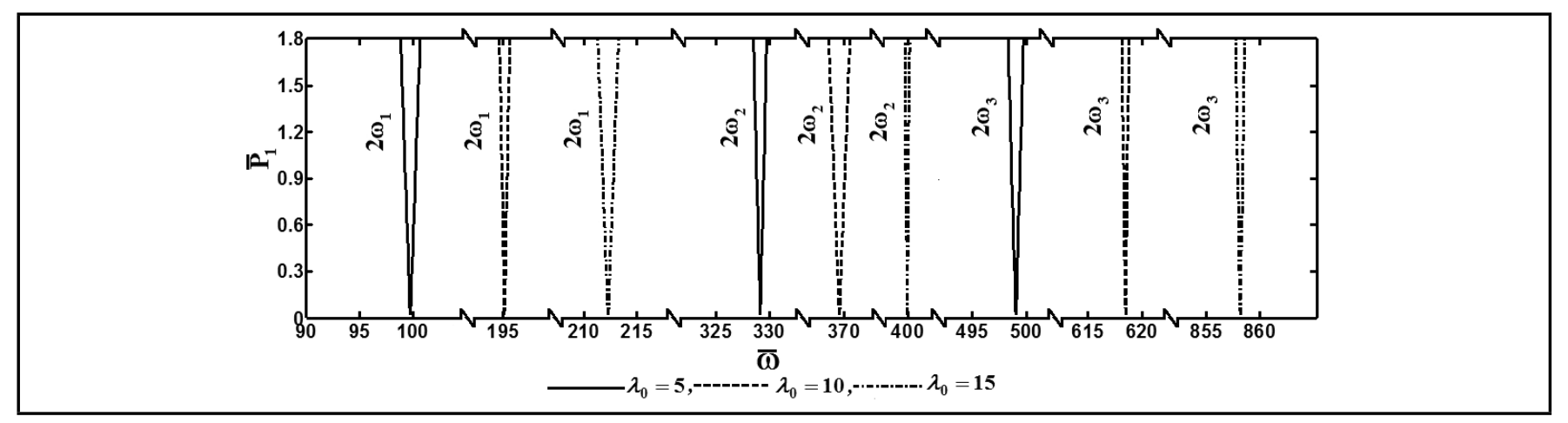

Figure 14. Effect of $\lambda_{0}$ on the instability zones.

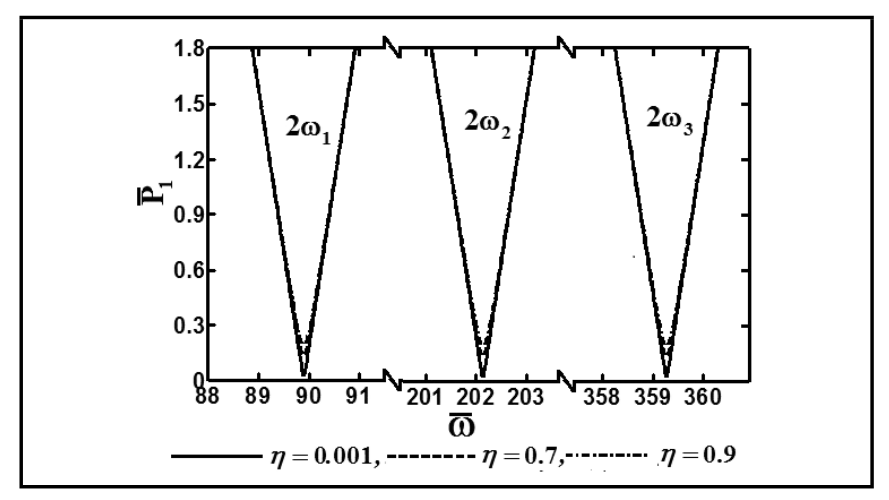

Figure 15. Effect of $\eta$ on the instability zones.

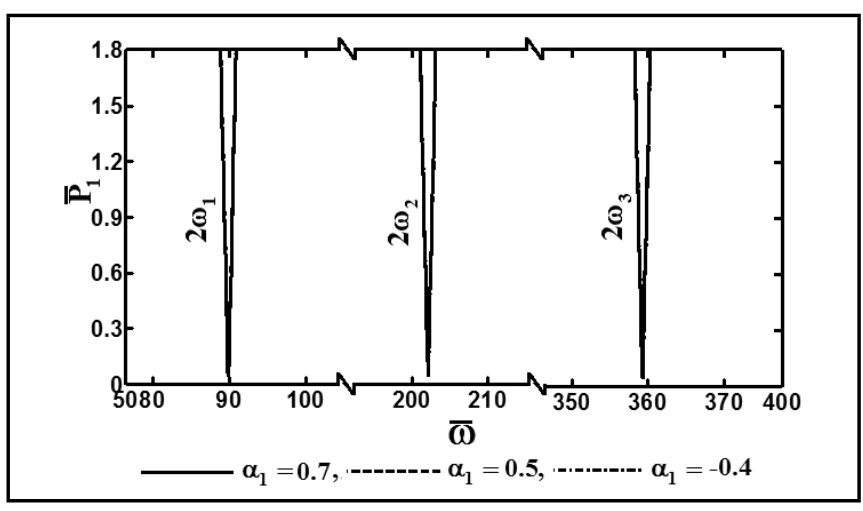

Figure 16. Effect of $\alpha_{1}$ on the instability zones.

of a radial beam with nonconstant angular velocity, Journal of Vibration and Acoustics, 109 (2), 138-143, (1987). https://dx.doi.org/10.1115/1.3269405

${ }^{4}$ Sri Namachchivaya, N. Mean square stability of a rotating shaft under combined harmonic and stochastic excitations,
Journal of Sound and Vibration, 133 (2), 323-336, (1989). https://dx.doi.org/10.1016/0022-460X(89)90929-2

5 Yokoyama, T. Parametric instability of Timoshenko beams resting on an elastic foundation, Computers \& Structures, 28 (2), 207-216, (1988). https://dx.doi.org/10.1016/00457949(88)90041-7

${ }^{6}$ Di Taranto, R. A. and Blasingame, W. Composite loss factors of selected laminated beams, The Journal of the Acoustical Society of America, 40 (1), 187-194, (1966). https://dx.doi.org/10.1121/1.1910037

7 Rao, D. K. and Stühler, W. Frequency and loss factors of tapered symmetric sandwich beams, Journal of Applied Mechanics, 44 (3), 511-513, (1977). doi: 10.1115/1.3424117

8 Asnani, N. T. and Nakra, B. C. Vibration analysis of multilayered beams with alternate elastic and viscoelastic layers, Journal of Institution of Engineers India, Mechanical Engineering Division, 50, 187-193, (1970).

9 Asnani, N. T. and Nakra, B. C. Vibration damping characteristics of multilayered beams with constrained viscoelastic layers, Journal of Manufacturing Science and Engineering, 98 (3), 895-901, (1976). https://dx.doi.org/10.1115/1.3439049

10 Asnani, N. T. and Nakra, B. C. Forced vibration analysis of sandwich beams with viscoelastic core, Journal of the Aeronautical Society of India, 24, 288-294, (1972).

${ }^{11}$ Ko, C. L. Flexural behavior of a rotating sandwich tapered beam, AIAA Journal, 27 (3), 359-369, (1989). https://dx.doi.org/10.2514/3.10120 


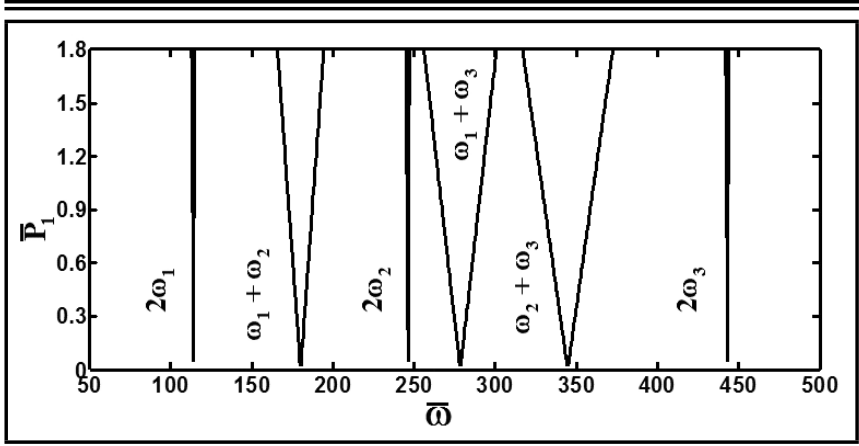

Figure 17. Stability diagrams for $\alpha_{1}=-0.4, g=0.01, \lambda_{0}=5, b=0.05$, and $\eta=0.1$

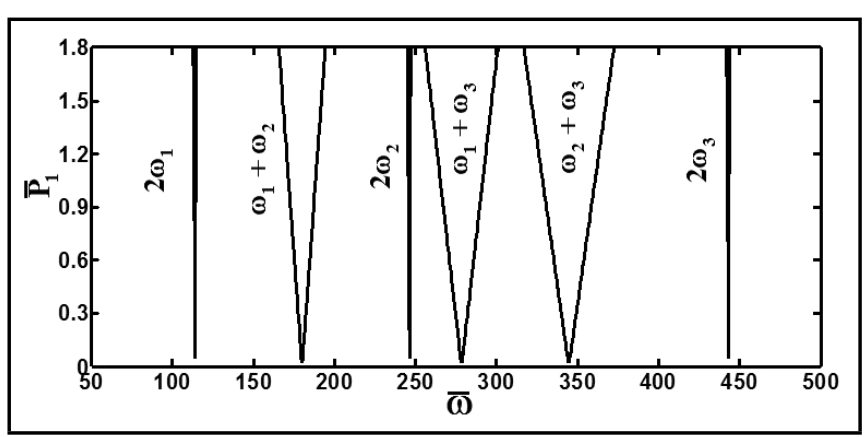

Figure 18. Stability diagrams for $\alpha_{1}=0.5, g=0.01, \lambda_{0}=5, b=0.05$, and $\eta=0.1$.

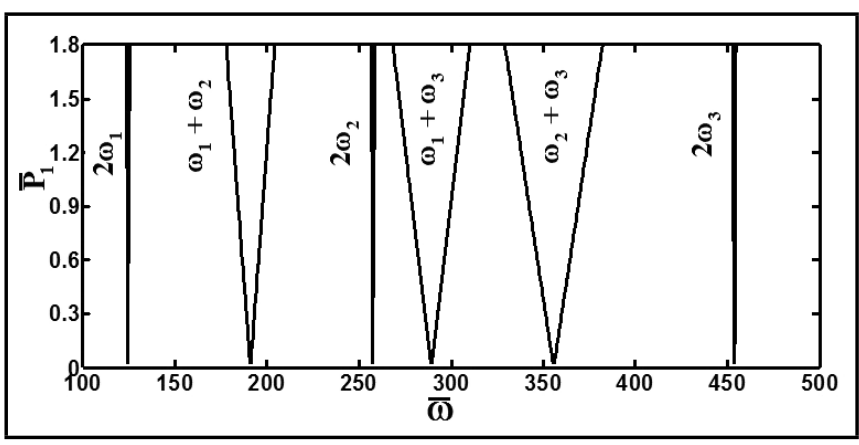

Figure 19. Stability diagrams for $\delta_{1}=0.2, g=0.01, \lambda_{0}=5, b=0.05$, and $\eta=0.1$

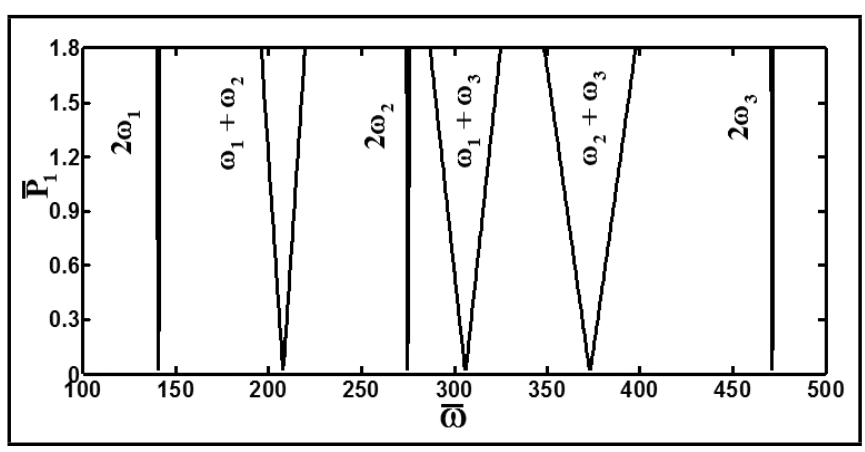

Figure 20. Stability diagrams for $\delta_{1}=0.8, g=0.01, \lambda_{0}=5, b=0.05$, and $\eta=0.1$.

12 Kar, R. C. and Sujata, T. Dynamic stability of a tapered symmetric sandwich beam, Computers \& Structures, 40 (6), 1441-1449, (1991). https://dx.doi.org/10.1016/0045-7949(91)90414-H

13 Ray, K. and Kar, R. C. Parametric instability of a sandwich beam under various boundary conditions,

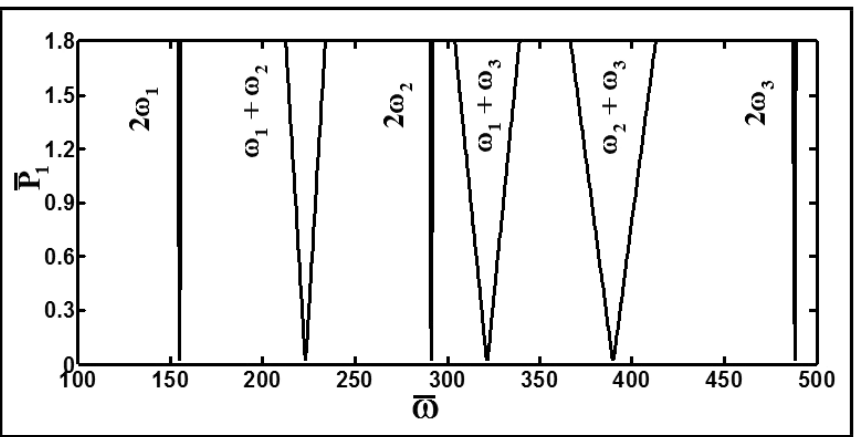

Figure 21. Stability diagrams for $\delta_{2} 1=0.2, g=0.01, \lambda_{0}=5, b=0.05$, and $\eta=0.1$.

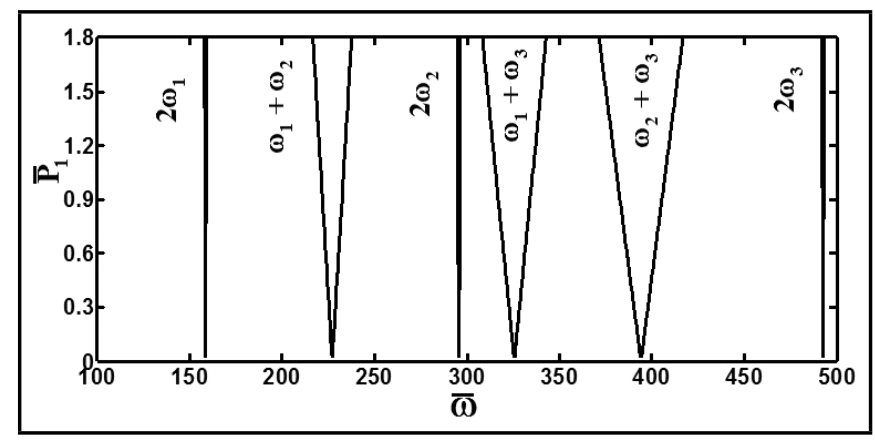

Figure 22. Stability diagrams for $\delta_{2}=0.8, g=0.01, \lambda_{0}=5, b=0.05$, and $\eta=0.1$.

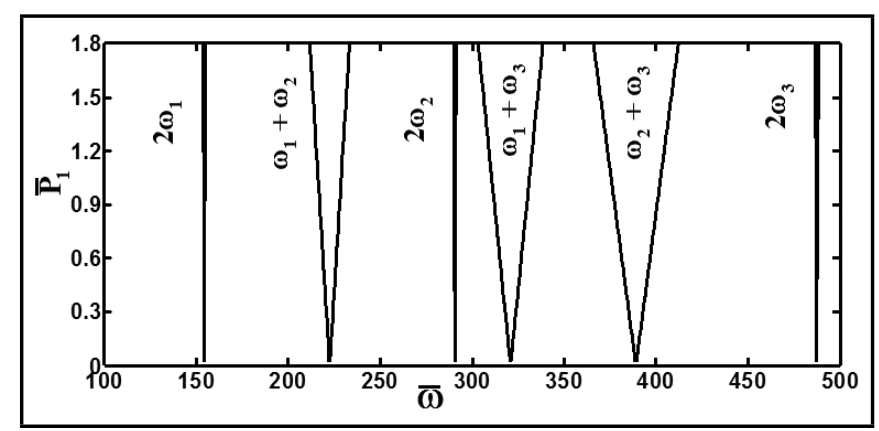

Figure 23. Stability diagrams for $b=0.05, g=0.01, \lambda_{0}=5$, and $\eta=0.1$.

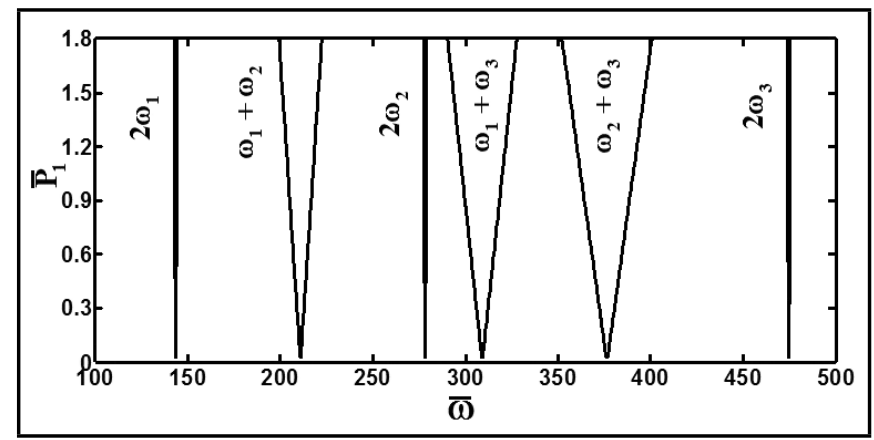

Figure 24. Stability diagrams for $b=0.1, g=0.01, \lambda_{0}=5$, and $\eta=0.1$.

Computers \& Structures, 55 (5), 857-870, (1995). https://dx.doi.org/10.1016/0045-7949(94)00427-5

14 Ray, K. and Kar, R. C. Parametric instability of multi-layered sandwich beams, Journal of Sound and Vibration, 193 (3), 631-644, (1996). https://dx.doi.org/10.1006/jsvi.1996.0305

15 Ishida, Y., Ikeda, T., Yamamoto, T., and Esaka, 


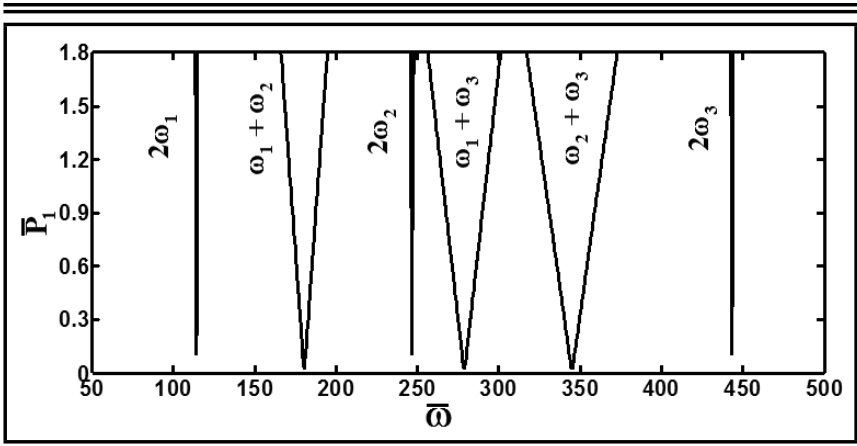

Figure 25. Stability diagrams for $g=0.05, \lambda_{0}=5, b=0.05$, and $\eta=0.1$.

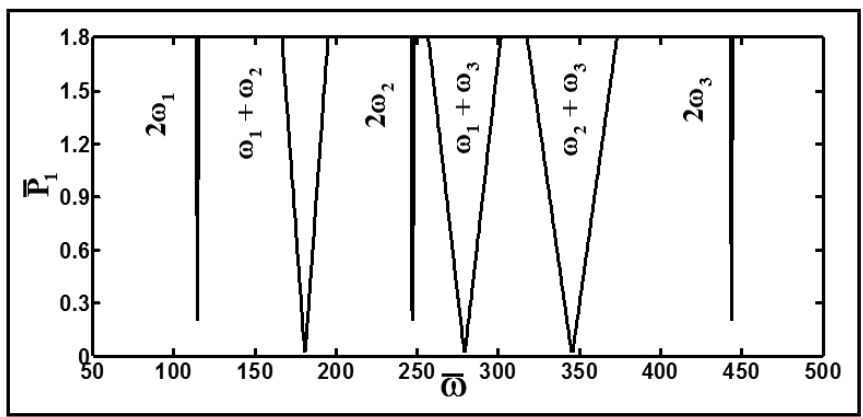

Figure 26. Stability diagrams for $g=0.1, \lambda_{0}=5, b=0.05$, and $\eta=0.1$.

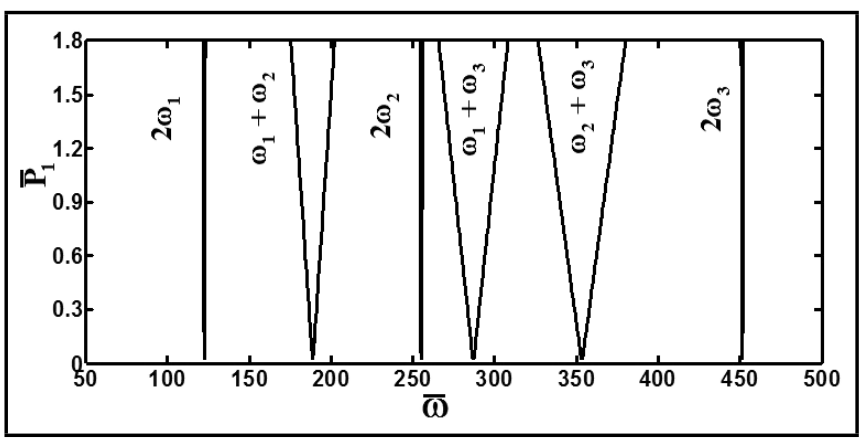

Figure 27. Stability diagrams for $\mu_{1}=0.05, \eta=0.1, g=0.01$, and $\lambda_{0}=5$.

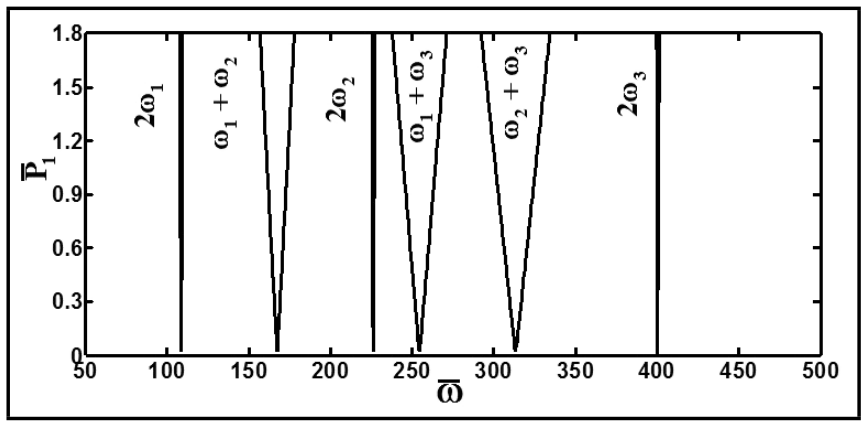

Figure 28. Stability diagrams for $\mu_{1}=0.5, \eta=0.1, g=0.01$, and $\lambda_{0}=5$.

T. Parametrically excited oscillations of a rotating shaft under a periodic axial force, JSME International Journal. Ser. 3, Vibration, Control Engineering, Engineering for Industry, 31 (4), 698-704, (1988). https://dx.doi.org/10.1299/jsmec1988.31.698

16 Kar, R. C. and Sujata, T. Dynamic stability of a rotating beam with various boundary conditions, Computers \& Structures, 40 (3), 753-773, (1991). https://dx.doi.org/10.1016/0045-7949(91)90243-F

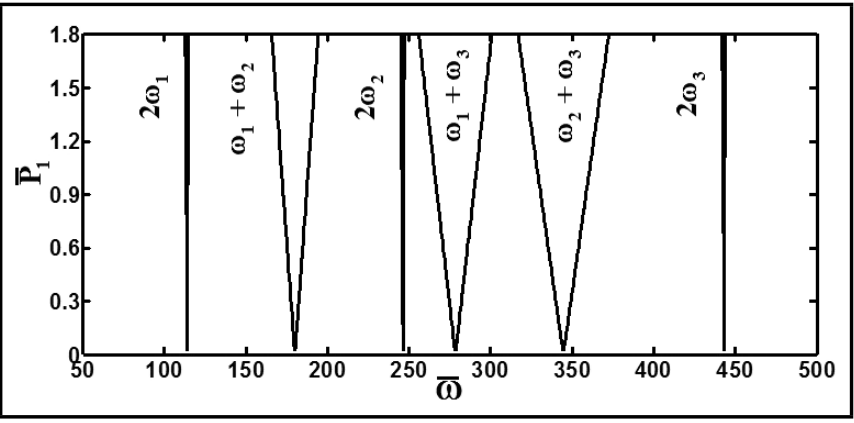

Figure 29. Stability diagrams for $\eta=0.01, g=0.01, \lambda_{0}=5$, and $b=$ 0.05 .

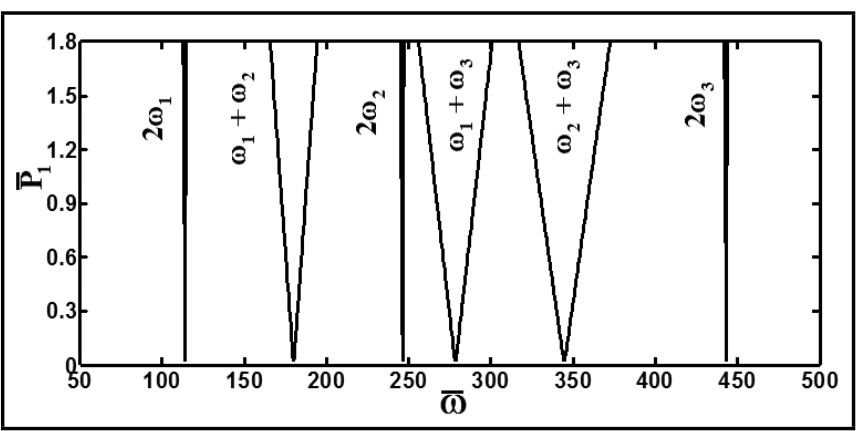

Figure 30. Stability diagrams for $\eta=0.1, g=0.01, \lambda_{0}=5$, and $b=0.05$.

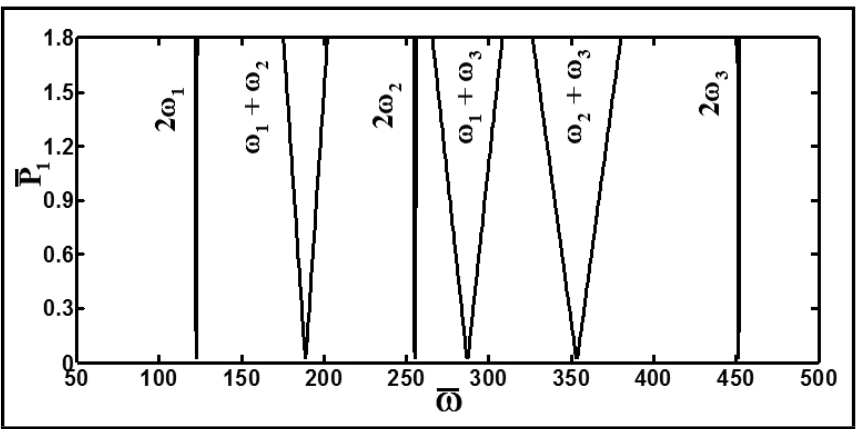

Figure 31. Stability diagrams for $\lambda_{0}=5, \eta=0.1, g=0.01$, and $b=0.05$

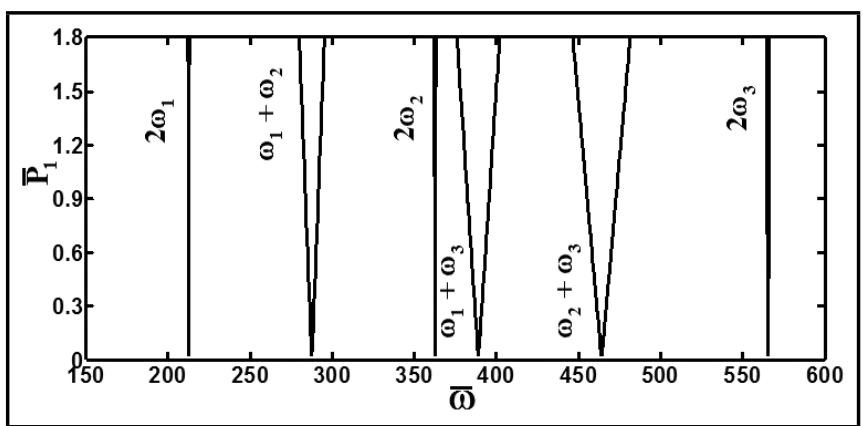

Figure 32. Stability diagrams for $\lambda_{0}=10, \eta=0.1, g=0.01$, and $b=$ 0.05 .

17 Kar, R. C. and Sujata, T. Parametric instability of Timoshenko beam with thermal gradient resting on a variable Pasternak foundation, Computers \& Structures, 36 (4), 659-665, (1990). https://dx.doi.org/10.1016/00457949(90)90081-C

18 Nayak, B., Dwivedy, S. K., and Murthy, K. S. R. K. Vibration analysis of a three-layer magnetorheological elastomer embedded sandwich beam with conductive skins 
using finite element method, Proceedings of the Institution of Mechanical Engineers, Part C: Journal of Mechanical Engineering Science, 227 (4), 714-729, (2013). https://dx.doi.org/10.1177/0954406212451812

19 Tomar, J. S. and Jain, R. Effect of thermal gradient on frequencies of a wedge-shaped rotatingbeam, AIAA Journal, 22 (6), 848-850, (1984). https://dx.doi.org/10.2514/3.8694

20 Lenci, S., Clementi, F., and Mazzilli, C. E. N. Simple formulas for the natural frequencies of non-uniform cables and beams, International Journal of Mechanical Sciences, 77, 155-163, (2013). https://dx.doi.org/10.1016/j.ijmecsci.2013.09.028

21 Lin, C. Y. and Chen, L. W. Dynamic stability of a rotating beam with a constrained damping layer, Journal of Sound and Vibration, 267 (2), 209-225, (2003). https://dx.doi.org/10.1016/S0022-460X(02)01427-X

22 Liu, W. H. and Yeh, F. H. Vibrations of nonuniform rotating beams, Journal of Sound and Vibration, 119 (2), 379-384, (1987). https://dx.doi.org/10.1016/0022460X(87)90463-9

23 Carnegie, W. The application of the variational method to derive the equations of motion of vibrating cantilever blading under rotation, Bulletin of Mechanical Engineering Education, 6, 29-38, (1967).

24 Rao, J. S. and Carnegie, W. Nonlinear vibration of rotating cantilever beams, The Aeronautical Journal, 74, 161-165, (1970). https://dx.doi.org/10.1017/S000192400004745X

25 Rao, J. S. and Carnegie, W. Non-linear vibration of rotating cantilever blades treated by the Ritz averaging process, The Aeronautical Journal, 76, 566-569, (1972). https://dx.doi.org/10.1017/S0001924000043876

26 Leipholz, H. Stability Theory, 2nd Edition, John Wiley and Sons, Chichestar, (1987).

27 Saito, H. and Otomi, K. Parametric response of viscoelastically supported beams, Journal of Sound and Vibration, 63 (2), 169-178, (1979). https://dx.doi.org/10.1016/0022$460 X(79) 90874-5$

28 Kerwin Jr, E. M. Damping of flexural waves by a constrained viscoelastic layer, The Journal of the Acoustical Society of America, 31 (7), 952-962, (1959). https://dx.doi.org/10.1121/1.1907821

29 Dash, P. R., Maharathi, B. B., and Ray, K. Dynamic stability of an asymmetric sandwich beam resting on a Paternak foundation, Journal of Aerospace Science and Technologies, 62 (1), 66, (2010).

30 Banerjee, J. R. Free vibration of sandwich beams using the dynamic stiffness method, Computers \& Structures, 81 (18), 1915-1922, (2003). https://dx.doi.org/10.1016/S0045-7949(03)00211-6
31 Caruntu, D. I. Simultaneous resonances of geometric nonlinear nonuniform beams, ASME 2009 International Design Engineering Technical Conferences and Computers and Information in Engineering Conference, San Diego, (2009).

32 Schilhansl, M. Bending frequency of a rotating cantilever beam, Journal of Applied Mechanics, 25 (1), 28-30, (1958).

33 Lo, H. and Renbarger, J. Bending vibrations of a rotating beam, Proc. of the 1st U.S. National Congress of Applied Mechanics, ASME, 75, (1952).

34 Dwivedy, S. K., Mahendra, N., and Sahu, K. C. Parametric instability regions of a soft and magnetorheological elastomer cored sandwich beam, Journal of Sound and Vibration, 325 (4), 686-704, (2009). https://dx.doi.org/10.1016/j.jsv.2009.03.039

35 Lenci, S. and Francesco Clementi, F. Effects of shear stiffness, rotatory and axial inertia, and interface stiffness on free vibrations of a two-layer beam, Journal of Sound and Vibration, 331 (24), 5247-5267, (2012). https://dx.doi.org/10.1016/j.jsv.2012.07.004

36 Parida, R. and Dash, P. Dynamic stability analysis of a circularly tapered rotating beam subjected to axial pulsating load and thermal gradient under various boundary conditions, International Journal of Acoustics and Vibration, 21 (2), 137-144, (2016). https://dx.doi.org/10.20855/ijav.2016.21.2402

37 Pradhan, M. and Dash, P. R. Stability of an asymmetric tapered sandwich beam resting on a variable Pasternak foundation subjected to a pulsating axial load with thermal gradient, Composite Structures, 140, 816-834, (2016). https://dx.doi.org/10.1016/j.compstruct.2016.01.010

38 Pradhan, M., Dash, P. R., and Pradhan, P. K. Static and dynamic stability analysis of an asymmetric sandwich beam resting on a variable Pasternak foundation subjected to thermal gradient, Meccanica, 51 (3), 725-739, (2016). https://dx.doi.org/10.1007/s11012-015-0229-6

39 Akgöz, B. and Civalek, Ö. Effects of thermal and shear deformation on vibration response of functionally graded thick composite microbeams, Composites Part B: Engineering, 129, 77-87, (2017). https://dx.doi.org/10.1016/j.compositesb.2017.07.024

40 Avcara, M. and Alwan, H. H. A. Free vibration of functionally graded Rayleigh beam, International Journal of Engineering and Applied Sciences, 9 (2), 127-137, (2017). https://dx.doi.org/10.24107/ijeas.322884

41 Avcar, M. Effects of rotary inertia shear deformation and non-homogeneity on frequencies of beam, Structural Engineering and Mechanics, 55 (4), 871-884, (2015). https://dx.doi.org/10.12989/sem.2015.55.4.871 